\title{
Las experiencias lúdicas, burlescas y festivas de los trabajadores y artesanos vascos preindustriales. Problemas de análisis y perspectivas de actuación
}

\author{
Juan Carlos EnRIQUuez*
}

RESUMEN

El presente ensayo pretende dar testimonio de algunas de las claves que caracterizaron la cultura lúdica y festiva del artesanado vasco. La primera parte analiza los rituales de contestación satíricos y burlescos tramados y desarrollados por las categorias populares para defender las normas tradicionales que reglaban las

relaciones sociales productivas. La

segunda propone un conjunto de orientaciones teóricas y metodológicas al objeto de conformar un programa de investigación integrado que evalúe los

impactos de la práctica del festejo histórico en las estructuras corporativas artesanas. Finalmente, el texto reflexiona sobre las experiencias

del "no trabajo" y los "descansos

frenéticos" protagonizados por los asalariados de los talleres preindustriales.
ABSTRACT

The main purpose of this essay is to give evidence of some of the keys which distinguished the ludic and festive culture of the Basque craftsmen. The first part analyses the satiric burlesque rituals of protest carried out by popular classes in order to defend the traditional norms that ruled social relations of production. The second one proposes a whole of theoretical and methodological guidances with the aim of constituting an integrated research plan that evaluates the incidence of the historical public festivities on the artisanal corporate structures. Finally, the paper thinks over the experiences of "non-work" and "frenzied days'rest” staged by employees of pre-industrial workshops.

- Universidad de Pau (Francia). 
Tras la irresistible ascensión y rápido olvido, a finales de la década de los setenta, de la vigorosa historiografía regional española, la irrupción de la "historia en migajas" no podía menospreciar un capítulo que podía dar pábulo y sentido a la emergencia con que pretendía legitimarse y erigirse aquello que ha venido en Ilamarse el Estado de las Autonomías. El estudio de la fiesta se consagraba como uno de los más recurrentes expedientes académicos para mostrar políticamente la reciedumbre identitaria de cada una de las comunidades - algunas paradójicamente adjetivadas de "históricas" - y regiones que vertebraban, a la vieja usanza orteguiana, España. Si hiciésemos un balance cuantitativo de los estudios que los novísimos departamentos universitarios, al menos en las ramas de las Humanidades, han emprendido o llevado a cabo en los últimos veinte años ya no podrá sorprendernos que la cuestión festiva, permitaseme la expresión, constituya una de las cuatro o cinco prioridades de la investigación histórica, etnográfica, sociológica o antropológica. La conjunción de la singular riqueza de nuestros archivos festivos y el dinero aportado por ayuntamientos, diputaciones, universidades y gobiernos de todo tipo, posibilitaron que el orden festivo reinara en las conciencias de todos los que, de alguna manera, participábamos en el festín. Los historiadores llegábamos a la fiesta con escaso o nulo bagaje teórico, pero con la fe y las ambiciones del converso. Casi todos éramos jóvenes y un tanto rebeldes. Descifrar los ocultos secretos de la práctica festiva sería nuestra causa. Era, de alguna manera, otra forma de comprometernos con la transgresión, ya que la fiesta era un comodín ubicuo que, además de conmovernos, podía drenar nuestro curriculum profesional en el contexto de una universidad expansiva, que ya no se cimentaba en el conocimiento, sino en los méritos de cada cual. Quien más, quien menos había leido a Heers, Caro Baroja y a ese crítico literario soviético, cuyo apellido era otra de las metamorfosis sintácticas y obsesivas de nuestros sueños de juventud, llamado Mijail Bajtine

Sí. La historia en migajas, máxime cuando la estructura de poderes instituidos ha actuado en su alrededor, ha convertido el estudio de la fiesta en un estereotipo plagado de tópicos, redundante en lo marginal y carente de sentido. Hemos sido presentistas hasta la médula, incapaces de articular su historicidad, de apuntar sus transformaciones y de presentar a sus protagonistas. Hasta tal punto nos han seducido sus formas y representaciones, sus puestas en escena y su teatralidad que al final hemos creído o considerado que la fiesta era un mero decorado, al que todos estaban convocados, bien como espectadores inconscientes y alienados para exaltar el orden político reinante o bien como antiguallas quiméricas para gozar las mieles delirantes de un fugaz mundo al revés. Y esto en el 
mejor de los casos, porque lo más frecuente es que nuestros trabajos sobre la fiesta adolezcan de estructura, de historia, de análisis y de interpretación. En primer término, tenemos que ser más exigentes con el vocabulario de la fiesta, asi como con los contextos sociales e ideológicos en los que aquélla se produce y desarrolla. Sé que es difícil ponernos de acuerdo sobre el concepto "fiesta". Los debates ultrapirenaicos no lo han conseguido. Esto no es un consuelo, porque aqui, entre nosotros, ni siquiera lo hemos intentado. Ante todo somos historiadores y tenemos que ser más rigurosos con los conceptos que provienen de otras disciplinas científicas. Quizás, para el estudio de la fiesta, la interdisciplinariedad sea tan inevitable como positiva, pero podemos desorientarnos o bloquearnos con conceptos tales como "ocio" o "tiempo libre", por citar una terminología empleada machaconamente a la hora de elaborar la práctica histórica festiva. Por otra parte estamos obligados a no encasillar la fiesta en unos tiempos determinados, a no asociarla exclusivamente a la periodicidad consensuada por la voluntad general y que queda expresada en el día del santo advocado. Para ello, tendríamos que cambiar nuestros enfoques, con análisis que hiciesen más hincapié o profundizaran en las experiencias culturales lúdicas de colectivos sociales más homogéneos. Y tendriamos que rechazar la idea de la fiesta como mero y único desahogo de presiones de los participantes en la misma. Preguntarnos cómo, de qué manera, cuándo o por qué festejaban nunca puede ser un interrogatorio artificioso o baladí. Las experiencias festivas y lúdicas colectivas se conforman como excelentes escaparates histórico-culturales muy útiles para cartografiar las señas de identidad de las distintas categorías sociales del pasado. Porque la fiesta es conmoción y conflicto, reivindicación y protesta, juego y agresión, risa y llanto, mediación, integración y exclusión y un largo y posiblemente interminable etcétera. El presente ensayo se organiza en dos partes claramente diferenciadas entre si. Ello no significa que sean opuestas, sino más bien complementarias. La primera, que se podría calibrar de coyuntural y narrativa, se ocupa de algunos de los rituales de contestación satírica instituidos por la cultura plebeya vasca para defender las normas tradicionales que reglaban las relaciones sociales productivas, haciendo un especial seguimiento de los charivaris laborales. La segunda, más estructural y analítica, propone algunas claves orientativas para el estudio integrado del complejo festivo desarrollado por el organigrama corporativo artesano, dando prioridad a la reflexión teórica y la actuación metodológica, con el objeto de conformar un programa de investigación que evalúe el papel central que supuso la práctica festiva como uno de los elementos que permiten hablar de la existencia, durante la Edad Moderna, de una específica Cultura Lúdica Artesana. Espero que las reflexiones que a conti- 
nuación expongo en torno a las experiencias culturales festivas de los artesanos y trabajadores vascos de la Baja Edad Moderna respondan a los objetivos que tan sucintamente he expuesto hasta aquí.

\section{1}

La vida cotidiana de las aldeas y villas vascas, durante los siglos XVII, XVIII y buena parte del siglo XIX, fue siempre compleja y la desigual distribución de la propiedad y la renta la hizo todavía más dura y difícil. Para el mundo del trabajo, a pesar de los seculares sufrimientos, los entramados históricos y culturales de la socialización popular siguieron reproduciendo, en líneas generales, los patrones comunitarios tejidos en la Alta Edad Moderna: las habladurías en torno a los nuevos matrimonios, los nacimientos, los galanteos entre jóvenes, el embarazo fraudulento de esta o aquella soltera, los sermones iracundos de los frailes predicadores, los altercados en tabernas y romerías, las mezquindades de taberneros, molineros o carniceros, los pequeños y asiduos robos de alimentos, las enfermedades del ganado, la cortedad de las cosechas, las ofertas raquíticas del mercado de trabajo artesano, la enésima huida de los aprendices de los talleres laborales, las frecuentes destrucciones de caseríos por el fuego, las desafecciones de la alta nobleza en el auxilio pecuniario de las fábricas eclesiásticas, las ferias anuales y de temporada o los mercados semanales. Todo este conjunto de hechos vivenciales, a los que podríamos añadir las casuísticas particulares o colectivas que puntualmente revelase la pertinente coyuntura histórica, inundaban el cosmos mental y comunicativo del conjunto parroquiano, en muchos casos sin distinción de clases sociales y entidades culturales. El palpable fatalismo moralizante con el que campesinos y trabajadores mecánicos vivian tales hitos cotidianos tenía, sin embargo, su punto de inflexión en la sorprendente capacidad que desarrollaron para trocarlos en desahogos lúdicos y por extensión, aunque fuesen fugaces, festivos. Para entender esta circunstancia debemos redimensionar los complejos burlescos y los múltiples calendarios festivos que se superponían y solapaban, a la manera de sedimentos y capas geológicas, en la vida de las categorías sociales productivas. De hecho, la ingente producción ideológica que en torno a la "arrogancia plebeya" generó la inteligencia ilustrada - para censurarla y reprimirla, por supuesto- tiene mucho que ver con la manera con que afrontaban los desheredados sus reveses cotidianos, casi siempre calamitosos, pero que también aparecían atravesados y sentidos por la memoria de la inversión, los ritos de la transgresión y los elementos jocosos de la quimera carna- 
valesca y festiva. Durante la larga fase preindustrial, los campesinos y los artesanos vascos, al igual que sus homónimos peninsulares y europeos, despidieron con alocada risa las noches del frío invernal (Santa Águeda), con peregrinaciones peticionarias en las que los cantos a la divinidad se fundían con estrofas soeces o laudatorias dedicadas a vecinos tacaños o bondadosos, el ayuno de la Cuaresma, la muerte, el Año Viejo y acogieron con no menos desbordante alegría los días del Carnaval, del Corpus Christi, la noche fecunda de San Juan, las fiestas del ciclo estival y de los santos gremiales, las matanzas de cerdos de San Martín, el Año Nuevo, los brutales días de nupcias, los sonidos secos y rítmicos del txistu y tamboril, las alboradas de las albocas, etc. Al mismo tiempo, las clases bajas fueron elaborando una cultura de la diversión que se extendia desde los cantos de oficios, los juegos de azar o las comilonas rituales a los variopintos encuentros de rudeza, tales como los desafios interpersonales, las guerras intraparroquiales, las vehementes coreografías danzantes que identificaban a cada comunidad en los días de las fiestas aldeanas, la lucha con bastones, el juego de frontón, la palanca, las pruebas de bueyes, los sokamuturrak, el levantamiento de piedras, etc., y espectáculos visuales, cada vez más populares y monetarizados, como las corridas de toros y las peleas entre animales, tan apreciadas por los oficios urbanos. Muchas de estas actividades festivas estaban asociadas al calendario agrario y laboral, las ferias de ganado, los mercados de grano, pescado, tejido, fruta y verdura y las festividades de los santos advocados por las distintas cofradías y barriadas de las anteiglesias y villas vascas. Desde luego, los festejos tabernarios, por sí solos, y a los que tan íntimamente ligados estaban los menestrales artesanos, conforman un capítulo específico.

Es verdad que muchas de las prácticas festivas enunciadas fueron hegemonizadas por la masa labriega, pero no es menos cierto que en su desarrollo y consolidación fue determinante la participación de los oficios mecánicos y de los trabajadores protoindustriales rurales, quienes con sus propias tradiciones lúdicas tendieron a reforzar y dinamizar el prolijo programa festivo subalterno. Buena prueba de lo que decimos es la visualización profesional que refleja la documentación vasca de los charivaris y de las múltiples y enmarañadas iniciativas festivas de carácter etnográfico. En ambos casos, la mezcolanza de campesinos y trabajadores manuales son su caracteristica más genuina y destacada. Tal circunstancia es, al mismo tiempo, probatoria de que la fiesta popular preindustrial no debe entenderse o explicarse como una sublime antigualla de meros encuentros colectivos, sino como un hecho histórico sin paliativos donde tiene lugar una intensa interacción social, un conglomerado de actividades y de ritua- 
les y un teatro donde se escenifica una densa transmisión de mensajes, muchos de los cuales se esfuerzan en estructurar o desbaratar las tupidas redes vivenciales y vecinales del orden social comunitario. ¿No es esto, quizás, lo que debemos inferir de la lectura atenta de las cencerradas vascas? Detrás de las risas y las burlas chariváricas, a menudo tan mezquinas como crueles, $y$ en las que eran tan participativos e imaginativos los campesinos y artesanos vascos, emergía una mecánica pedagógica de símbolos que se orquestaban para defender los derechos comunes y consuetudinarios de la comunidad, para denunciar a las jóvenes escandalosas, para repudiar a los mozos arrogantes, para estigmatizar a las mujeres autoritarias o de vida alegre, para acusar y avergonzar a los maridos sexual y socialmente complacientes con los desvaríos amorosos de sus consortes, para penalizar las estrategias matrimoniales inauditas, para reprobar las conyugalidades entre viudos, para perseguir las arbitrariedades ejecutadas a la economia moral de la multitud, para mofarse de las prácticas gubernativas impopulares, para combatir a clérigos intolerantes, amos despiadados, arribistas y meritorios amorales, maestros violentos y autoridades despóticas, para alcanzar -en definitiva - la utopía colectiva y liberadora de un mundo reglado por el paradigma de las reprimendas humorísticas. Porque, en efecto, contra tal ejército de arrogantes desestructuradores, la cultura social lúdica popular concitó la teatralidad festiva, siempre normativa, simbólica y valorativa, es decir, todo un expansivo aparato de gestos, palmoteos, risotadas, pelelizaciones, titirizaciones, cabalgatas, apedreamientos burlescos, salivazos, rituales crucíferos, bailoteos injuriosos, sonidos onomatopéyicos, canciones sardónicas, músicas obscenas y ridículas, gritos, insultos festivos, etc., con la finalidad de modelar y organizar un orden horizontal, cotidiano y comunitario en el que el poder político y social y las expectativas económicas de cada cual estuviesen reconocidas y compartidas por el bloque vecinal, popular y laboral. Creo sinceramente que lo dicho líneas arriba quedará evidenciado de manera palmaria con el análisis y exposición del siguiente charivari laboral acaecido en la barriada bilbaína de Bilbao la Vieja la tarde-noche del 6 de octubre del año 1800.

Delante de la casa de Don Pedro Isaac de Echebarria, un próspero artesano comerciante de la barriada, ante una crecida muchedumbre de vecinos que según los testigos aumentó vertiginosamente, Francisca Uriarte, mujer de Antonio Arteche, un herrero del citado barrio, procedió chariváricamente a revelar la creciente distancia que se estaba dando entre uno de los primeros empresarios de la era contemporánea y sus trabajadores. Y lo iba a hacer en clave de lo que he denominado reprimenda humorística. De nuevo, aquí, el teatro de calle, tan esencial y característico en las socie- 
dades comunitarias, adoptará la función de denuncia pública, pero el sentido procesional quedará diluido por la fuerza de la parada burlesca. Una mujer, Francisca, procederá a injuriar "festivamente» al patrón de su marido, propalando dicterios y repitiendo cantinelas jocosas en medio de la hilaridad de un ghetto obrero que se mofa, vibra y se alboroza sarcásticamente con las producciones lingüísticas de una de sus convecinas:

\begin{abstract}
"La acusada es una mujer de lengua mordaz y muy ligera en sus manifestaciones, tanto que anteriormente ha sido corregida por los tribunales por detractora, levantadora de voces y alborotadora, como lo tiene de costumbre, sin acordarse del pan que le ha hecho ganar a su marido, siendo por lo mismo mayor el delito que la ignominiosa afrenta...El afrentado concluye el defensor de Echebarria- es un hombre que ha obtenido empleos públicos en la Villa de Bilbao y su llustre Consulado y la afrenta fue cometida en público" '.
\end{abstract}

¿Cómo un empresario que "daba de comer», según refiere el texto, a un ínfimo herrero podía ser tan vilmente insultado por una mujer díscola?, ¿cómo un sujeto que había merecido el aprecio de los mejores y más acaudalados caballeros de la villa, llegando incluso a obtener cargos honoríficos de República y de su poderosa y omnipotente Casa de Contratación, podía ser humillado tan cruelmente por una charlatana de la chusma?, ¿cómo un hombre tan honorable podía mirar a sus honrados convecinos cuando la afrenta habia sido concebida conscientemente, ejecutada delante de su caserón, de su taller, jaleando además la hilaridad de todo un barrio? Antes de oír a Francisca, conviene detenernos un instante para disponer de algunas referencias contextualizadoras de uno de los suburbios más importantes de la villa vizcaína. Junto con Achuri y Ascao, Bilbao la Vieja o "Allende el Puente" - conformado por los cuarteles de Urrazurrutia, Cantarranas, San Antón, Bilbao la Vieja y plazuela de Andico Campo-, desde los siglos bajomedievales, se fue conformando como una cloaca social en la que convergian campesinos excluidos del hogar familiar, obreros no cualificados, prostitutas provincianas, oficiales recién casados, toda la arriería cántabra y castellana, la masa lumpen, desde el pequeño ratero de alimentos y vestidos hasta la partida de bandidos organizados que contrabandeaba muselinas británicas y tabacos americanos, y una legión de mendigos harapientos que, por carecer, carecian hasta de la memoria de su patria de nacimiento. Digamos que Bilbao la Vieja era el patio trasero, como lo sigue siendo actualmente, de aquella

\footnotetext{
265 n 032 .

Archivo Histórico Diputación de Vizcaya (A.H.D.V.). Corregimiento de Vizcaya (C.V.). Legajo
} 
floreciente villa comercial e industrial, tan loada por los viajeros extranjeros y nacionales de los siglos XVIII y xix. Hacia el año 1800, las callejuelas de Bilbao la Vieja eran un hervidero superpoblado y sobreexplotado compuesto por una infinidad de oficiales artesanos y trabajadores no especializados, de calafates, embaladores, regateras, cargadoras del puerto, jornaleros, entalladores, curtidores, zapateros, costureras, sastres, albañiles, cesteros, criadas, zurradores, carpinteros, silleros, lavanderas, claveteros, polleras, cigarreras y una pléyade de herradores, taberneros, policias forales, serenos y funcionarios carceleros. Porque, lógicamente, la cárcel del Señorío de Vizcaya también encontró su real emplazamiento, como una cruel paradoja, en tan singular y variopinto espacio económico, laboral y social. Los contados fabricantes, maestros artesanos, comerciantes y escribanos que habitaban en el barrio no debieron, en principio, hacer excesivos ascos a convivir con el populacho, sin duda impelidos por los delirantes alquileres exigidos por las veinticinco o treinta familias que constituian la Junta de Propietarios de Bilbao, únicos y verdaderos amos de todo el suelo, subsuelo e inmuebles de la jurisdicción vizcaína. En esta barriada era excepcional la noche o el día en que no sucediese algún grave altercado. La cohesión social y comunitaria fue siempre difícil porque, como lo demuestra el Censo de Policía de 1825, las dos terceras partes de las familias consignadas eran inmigrantes y muchos entendieron su estancia o presencia allí como una mera etapa de tránsito a lugares con mayores ventajas o mejores expectativas. Esto en el mejor de los casos, ya que entre 1760 y 1840 , el encarecimiento de los alquileres, el hacinamiento, la desigualdad de la carga tributaria, siempre más voluminosa para las categorías sociales humildes, la imposición fiscal sobre los consumos de primera necesidad, la interrupción del giro comercial e industrial por las guerras, fuesen internas o externas, la impertérrita crisis agraria y el paro cíclico en los oficios artesanos, lejos de descargar el barrio de tan peligrosa masa humana, la multiplicó. Oleadas de nuevos trabajadores, muy golpeados en sus parroquias de origen, fueron tragados por una tenaza que devoraba sin conmiseración la subsidiariedad al tráfico comercial de muchos de los oficios enumerados arriba o la venta de la fuerza de trabajo en actividades protoindustriales de filiación siderúrgica y textil. Sin embargo, en aquel tiempo, cuando empezaba a respirarse una nueva disciplina en el trabajo, nunca dejarían de oírse los gritos de la pobreza y la marginación. Es en este contexto, desde lo más alto si se quiere, donde debemos ubicar a nuestra nunca olvidada Francisca. Ella, en exclusiva, iba a protagonizar un "sainete popular" en el que todos sus actos estaban revestidos de un halo de comicidad festiva y reivindicativa, y así, en medio de los exabruptos e insultos, la mujer del herrero, como si se tratara de 
una salmodia de las beatas de la cercana parroquia de San Nicolás de Bari, repetía incansable "que a los oficiales que debia pagar siete u ocho reales diarios los tenía por seis y que tenía que haber en el Don Pedro de la mierda parte de lo que había ganado su marido". Y puesta en jarras, para hacer más hirientes y creíbles sus acusaciones, ya que toda la vecindad la estaba contemplando, afirmaba vehementemente "que el tal don Pedro era un mal hombre, falso, un grandisimo bergante, que cuando iba a (la parroquia de) San Francisco a rezar debía llevar cuernos sobre la peluca y que también ella comprando cuatro libras de harina se pondria peluca».

Lógicamente, todas sus exclamaciones y críticas iban acompañadas de aspavientos, golpes en el suelo, manos conformando cuernos, muecas groseras y posturas zafias. Durante cuatro horas, desde las seis de la tarde hasta las diez de la noche, todo el arrabal contempló el charivari con una complacencia no disimulada. $Y$ aunque hubo instantes en que los espectadores, según reconocieron algunos testigos en la sumarial abierta para diligenciar el caso, no pudieron captar los gritos de Francisca por las risas y bullicio de niños, mujeres y ganapanes que llegaban a la barriada concluida la jornada laboral, todos los asistentes al mismo asumieron que detrás de la escenificación sardónica y festiva emergía toda una suerte de tradiciones bufonescas con las que la cultura subalterna reivindicaba actos concretos de probidad y justicia en las relaciones sociales y económicas que trenzaban la vida comunitaria. Es difícil no reconocer que la paciencia de Francisca habia llegado a su límite. Esta mujer de "genio vivo y alborotado" - tal como la definió Javier Achurriaga, un oficial herrero compañero de Arteche- estaba harta de que el menguado salario de su marido no alcanzase la alquimia de unos precios vertiginosamente al alza. Con todo, fue capaz de discernir al culpable de su situación y lo hizo en clave laboral, cultural y, ¿por qué no decirlo?, de clase. Porque la acción charivárica se fue fraguando en la ardiente cotidianidad de la pobreza. A través del "débil tabique y puerta" que separaba las habitaciones de dos familias, María Josefa Aldecoa, una viuda sesentona, pudo escuchar durante meses las recriminaciones nocturnas que Francisca lanzaba a su consorte: con el dinero de su jornal no podían seguir viviendo. ¿Qué hacer? Ella, que no era una dama, que desconocía las reglas de la urbanidad y del respeto que imperaban en los salones del patriciado ilustrado vasco, como mujer de la plebe que no se mordía la lengua, que habia crecido y se habia fortalecido en los combates callejeros contra sus convecinas, que sabía de memoria el vocabulario de las regateras del mercado mayor y menor de Bilbao y los vocablos mordaces y burlescos del puerto, que vivía y conocía todos los recovecos de la cultura plebeya y que participaba de todos sus ri- 
tuales y simbologías, comenzó a verlo muy claro: iba a proclamar públicamente, con valentía, lo que cada noche repetía en la oscuridad de su alcoba, es decir, que el patrón de su marido era un ladrón engreído. En su acción no hay nada sorprendente ni novedoso. Ni en un ápice se aleja de los rituales cómicos con los que las categorias populares precapitalistas trataban de imponer sus particulares conceptos de justicia retributiva. Echebarria se había excluido de las reglas societarias y debia pagar su incoherencia públicamente. En su sentencia, Francisca repasa con escrupulosidad los cargos que le habian determinado a ejecutar su castigo. En primer lugar, Don Pedro era culpable de un robo sistemático en los haberes diarios que debia percibir su marido. Robo que, en la coyuntura dramática del año 1800, era todavía más ofensivo porque, a la par que Echebarría producía mercancias y en consecuencia se enriquecia, sus operarios veían menguada su renta laboral con respecto al ininterrumpido beneficio del proceso productivo y al coste real de la vida. En segundo término, Don Pedro era culpable de prepotencia. En la aparatosidad de las expresiones de "hombre bergante, malo y falso", vertidas por la mujer del herrero frente a su casa, se escondían los viejos valores y las normas heredadas de un mundo del trabajo y de un concepto de cosocialización popular que empezaban a dar claras señales de agotamiento. Francisca lanzaba acusaciones a un hombre que debía recuperar la "senda de la virtud» - un concepto paternalista reiteradamente usado por las autoridades forales para "solventar toda clase de conflictos sociales"- y actuar en consecuencia con todos los deberes y obligaciones que ello comportaba. Dicho de otra manera, Francisca reivindicaba un amo deferente y paternal y no un patrón distante y egoísta. Finalmente, Don Pedro era culpable de engreimiento. Francisca refuerza su cargo con la estética corrosiva de la peluca. ¿Por qué iba a enmudecer cuando estaba harta de ver a miles de mujeres como ella que estaban abocadas a vestir de por vida paños gruesos, mitones viejos, lienzos descoloridos, pañuelos rotos o camisas deshilachadas a fuerza de lavarlos? Don Pedro era el pavo real que se distinguía de sus oficiales, aprendices y de los vecinos del barrio con un aditamento de la moda patricia, sobre el que esta mujer regañona y alborotadora colocará unos soberanos cuernos. Claro que, simbólicamente, eran los cuernos del cornudo, del cabrón, del que es engañado por su mujer. Aun así, la desacreditación de Echebarria llega a su máximo clímax cuando la mujer del herrero espolvorea sus melenas con harina, con esa harina por la que ella luchaba tan tenazmente cada día y que, como una cruel ironía, un hombre solo usaba para embellecer su figura, vanidad y poder en los bancos de la iglesia de San Francisco Extramuros de Bilbao cuando en las primeras horas de cada mañana acudia a oír los oficios divinos y, posiblemente, pedía perdón por todos sus pecados. 
El ritual burlesco, lúdico y acusadamente festivo que acabamos de analizar muestra que la relación explotadora es algo más que la suma de lamentos angustiosos y antagonismos mutuos. Es verdad que tales conflictos se insertan en la experiencia cotidiana de unas relaciones sociales de producción que constreñían a la masa trabajadora preindustrial y buscaban cosificarla, atomizarla y despersonalizarla. El hecho de que la población obrera y sus familias sintiesen tan apasionadamente los agravios nos obliga a recordar que muchos de los enfrentamientos sociales y económicos de aquellos siglos no pueden ni deben incluirse en los expedientes asépticos y cuantitativos del coste de la vida. Reiteramos, valores como la igualdad, la independencia, la reciprocidad, la justicia, etc., fueron a menudo defendidos por acciones mordaces y rituales chariváricos por parte de la masa obrera y campesina. Es posible que los trabajadores de Olabeaga, de la ribera de Deusto, muy próxima a Bilbao, se burlasen de todos aquellos que merodeaban por sus inmediaciones, pero con Manuel de Sancha, asistente-secretario de Don Pedro Goossens - fiel regidor y potentado comerciante de la anteiglesia citada y de la villa de Bilbao-, los trabajadores del puerto llegaron a inundar imaginativamente el modelo satírico y festivo de la cencerrada obrera y política. La acción tuvo lugar el dia de San Ignacio (31 de julio de 1773), es decir, una fiesta de precepto litúrgico y de descanso obligado para todos los vizcaínos, excepto para unos obreros que debian descargar la lana de uno de los incontables navios fondeados en la ría bilbaína:

«Al pasar por la Ribera y el muelle donde estaban estibando varios navíos - señala Sancha- por varios hombres solteros de esta república, algunos de ellos, sin que hubiese habido el menor motivo ni hablado conmigo, comenzaron a cantar: 'Sancha payaso, Sancha arlote payo, pícaro, canalla, engañador, falso y borracho. Has destruido la mitad de la República. Vete, vete, vete, a casa de la viuda y empreña a la madre y a la hija'. De modo que oyéndolo quedé turbado y asustado y aunque tales de la estiba no explicaron quienes eran la viuda y su hija, tengo para mi seria por Josefa de Arana y Francisca de Goiri y Arana, que viven en la cercanía de la casa-cervecera, porque suelo ir a casa de las susodichas (a pasar) un rato de buena conversación"?

La algarabía festiva de los jóvenes trabajadores, todos solteros, fue reforzada, según atestiguó Domingo Larrea, con el estruendo de un "cuerno de bocina y poniendo las manos en la boca" para agudizar los sonidos y los tonos de la estrofa injuriante. Incluso, algunos de ellos, los apodados 
Mazo y Fraile, adoptaron mientras gritaban y cantaban las poses, con fardos de lana, de las mujeres embarazadas. Está claro que nos encontramos, de nuevo, con un conjunto de representaciones y experiencias que forman parte del léxico lúdico-despreciativo y del ritual cómico popular, lo que nos induce a afirmar que las tipologías burlescas ejecutadas por los colectivos productivos subalternos merecerian en el futuro un tratamiento historiográfico más sistemático y adecuado. Con los improperios lanzados por los trabajadores - y que Sancha entendió como insultos- quedaba erigida una escalera de sanciones desvalorativas, por mucho que fuesen catalogadas como simple chanza por el carpintero Rementería, otro testigo del suceso ${ }^{3}$. ¿A qué tipo de sanciones nos referimos? Digamos que no es casual que el asistente del fiel optase, en primer término, por dar parte a las autoridades municipales y les demandase, más tarde, en Bilbao. La ceremonia, en el breve lapso de unos minutos, había recorrido con fuerza injuriante y burlesca a la mayor desacreditación que un hombre podia padecer. Los insultos que había oído y los ademanes que había visto eran lo suficientemente denotativos como para callar en el silencio su susto y turbación. Su posición y prestigio social habían sido quebrantados. Ciertamente, detrás de los vocablos de arlote, canalla, engañador, etc., en ningún caso vertidos accidentalmente, se escondían términos que evocaban algunas modalidades delictivas de la persecución policial de las clases dominantes, aunque en este caso no estuviesen adornadas por la parafernalia de los tribunales de la judicatura del Estado Absoluto, sino en el contexto del contrateatro de la mofa y del ridículo que privilegiaba la cultura popular. Sancha quedaba confundido con los hombres que vivían en el cosmos de la delincuencia común. Podría servir al poder, pero era un "falso republicano»; podría ayudar a las autoridades, pero era un "pícaro vecino"; podría codearse con los hombres más ricos y distinguidos, pero nunca dejaría de ser un pelele del orden, un "arlote» en manos del patriciado; podría diligenciar contra artesanos, jornaleros y campesinos por alborotadores de tabernas, pero él siempre sería un «borracho» solitario de cualquier habitación silenciosa. Todo ello excluía a Sancha de un concepto popular de relaciones sociales que exigía deferencias y contraprestaciones. El discurso charivárico, que en este caso se inserta en un contexto laboral donde los trabajadores desplegaban sus iniciativas burlescas, lúdicas y festivas, acababa no obstante de comenzar. Sancha era excluido porque sus manejos en la administración local deustarra habían perjudicado y marginado a la mayoría de la vecindad. El sentido político de la

"Con frecuencia los que trabajan en los navios burlan y dicen lo que se les antoja a los que andan por la Ribera, lo cual se entiende entre estibadores como chanza" (ibidem). 
frase "has destruido la mitad de la República", aunque fuese enunciada en medio de risotadas y excesos procaces, es reveladora de la incuestionable apuesta moral que las clases laborales concedian al ejercicio del poder y la gestión comunitaria. Manuel de Sancha se había evadido de sus obligaciones como funcionario municipal para favorecer la estructura clientelista y las prácticas caciquiles que se desarrollaban tanto en el interior como en el exterior de la anteiglesia vizcaína, las cuales llegaron a socavar las relaciones de reciprocidad moral entre los vecinos. Todo ello había supuesto la destrucción de parte del complejo territorial comunitario y, en consecuencia, la conformación de un espacio económico con menores expectativas para cualquier iniciativa privada o colectiva de las clases más desheredadas de la aldea. Porque, en ningún caso, los estibadores estaban afirmando con su chanza festiva que la mitad de la jurisdicción de la República se hubiese evaporado e desaparecido por arte de magia. Cuando Enrique Aresti, Gabriel Ugalde, José Olascoaga y Domingo (a) Mazo, con un profundo sentido bufonesco, cataban tales incriminaciones, le estaban recordando a Sancha que sus manejos habían servido sólo a una minoría, en la que incluían, sin nombrarles, a su amo Goossens, a los hermanos Arauco, al jauntxo Goicoechea y a pocos más, únicos que tenían la capacidad económica de alquilar, primero, y cerrar - léase mejor, privatizar-, más tarde, las fructíferas vegas hortícolas de la ribera de Deusto, usadas para la producción de chacolí y productos frutícolas, o la potestad política de enajenar a bajo coste, sobre todo en los últimos decenios del siglo XVIII y primeros del XIX, numerosos lotes de tierra, donde la burguesía bilbaína mostraría su poder al mundo levantando casas de recreo y palacetes de verano, siendo esta dinámica muy similar en Abando, Begoña, Santurce, Portugalete, Baracaldo y Guecho, es decir, el hinterland y la ría bilbaínos.

La culminación del agravio es una recreación sobre una conducta sexual que se alejaba de las normas proclamadas y defendidas por la ideología patriarcal de las categorías sociales dominantes, tan arraigada en las conciencias populares y fuente inagotable para la expansión de las distintas cencerradas punitivas desarrolladas por la cultura subalterna. Con la expresión "vete, vete, vete a la casa de la viuda y empreña a la madre y a la hija", Sancha es acusado de mantener una vida sexual preconyugal agitada. Nada menos que con una viuda y su hija. De nuevo, otra moralización idealizadora de un presunto desorden es aireado y corregido públicamente. Los estibadores censuran un comportamiento deshonroso, con la clara intención de castigar y deslegitimar a un transgresor. De castigar a un hombre capaz, al mismo tiempo, de amar a una moza y seducir a su madre; de deslegitimar a un transgresor que ha quebrantado la problemá- 
tica armonía de las relaciones sociales, las normas sexuales y las estrategias matrimoniales en el interior de una comunidad preindustrial que se autoafirma machaconamente católica. Creo, con las dos casuísticas analizadas, haber demostrado que el tiempo del charivari, como ritual de escarnio, risa y castigo, también se inscribe en el tiempo del trabajo; que los espacios cómicos son aleatorios y no están predeterminados por la existencia de un calendario que fija rígidamente cuándo y de qué manera se debía vivir y sentir la fiesta y, finalmente, que los trabajadores precapitalistas recurren a rituales y simbologías burlescas para reivindicar algo más que el pan cotidiano. No hace falta remarcar aquí que cuanto más fructífero pueda resultar el análisis, estudio y debate sobre los niveles de vida de las categorías populares durante la larga fase de la crisis del Antiguo Régimen, mejor conoceremos sus rituales de protesta, sus politologías festivas y sus simbologías de escarnio, así como ese denso magma de experiencias burlescas todavia por descubrir que encierran nuestros archivos judiciales y que no dudaría en calificar como las reprimendas humoristicas de la cultura artesana y trabajadora. En todo caso, a modo de colofón, lo que interesa subrayar aquí es que el charivari laboral se instituyó como el último peldaño de una prolongada escalera de ofensas soportadas por los asalariados y sus familias con un silencio clamoroso. Cuando ya no pudieron soportarlo más, con frecuencia activaron los mecanismos de la revuelta y de la protesta, pero también supieron desarrollar representaciones históricas inundadas de risas hirientes y repudios histriónicos sin sangre.

\section{II}

Evaluar y sistematizar estas mecánicas de rituales satíricos desarrollados por las categorías populares obreras es un reto que la historiografia española no puede obviar o dejar al margen de los cimientos conformadores de la cultura del trabajo subalterna. El estudio de la práctica festiva, con todas sus expresiones y tipologías, puede ser idónea para revelar sus entramados y particularidades. En realidad, estamos hablando de experiencias adaptables a casuísticas especificas. Cierto es que todavía estamos empezando a vislumbrar que el caleidoscópico mundo del corporativismo gremial urbano no quedó circunscrito a reglamentar el trabajo, la producción y la difusa y opaca circulación de mercancias artesanales. Iba mucho más lejos, hasta el punto de conformarse como institutos comunitarios que guiaban y encuadraban las experiencias comunes de vida y existencia de sus integrantes. Hablar de experiencias 
comunes es sumamente complicado, en buena medida porque la documentación histórica nos proyecta imágenes tan diversas y dispares que no es gratuito hablar, con harta frecuencia, de un rompecabezas contradictorio. Las corporaciones artesanales eran instancias disciplinadoras que encorsetaban al conjunto de sus miembros. Sus propias estructuras reforzaban el poder de sus cuadros dirigentes (maestros), en detrimento de los trabajadores directamente relacionados con el proceso productivo (oficiales y aprendices). Ahora bien, quedarnos con esta idea es de alguna manera falsear la realidad histórica. Los gremios fueron muy dinámicos en favorecer los encuentros lúdicos y las fiestas. Con ellos, las hermandades de trabajo minimizaban las asperezas jerarquizadoras que atravesaban la cotidianidad del taller, al tiempo que conformaban nexos de identificación y orgullo en la práctica del ejercicio de los oficios. Si empezásemos a entrever que la existencia de un prolijo calendario festivo artesanal, que la presencia en las calles de los agremiados en paradas, peregrinaciones y romerías devocionales, que la participación en fiestas organizadas y regladas por los ayuntamientos, no sólo tenian un profundo sentido lúdico y cultural sino que trababan la solidaridad del grupo como entidad moral y como soporte institucional de las relaciones intravecinales, entonces podríamos superar el estereotipo calamitoso que nuestra propia práctica del oficio de historiadores ha llegado a recrear y enaltecer en los manuales y ensayos universitarios, esto es, el gremio artesano visto exclusivamente como entidad cerrada, dotada de mecanismos de exclusión social y reglamentaciones discriminatorias, donde sólo cabía el trabajo y la cultura festiva era una expresión menor, sin la fuerza y la capacidad lubrificadora de, por ejemplo, la fiesta mo nárquica, posiblemente la única tipología festiva que ha merecido una atención desorbitada por parte de nuestra más reciente historiografía. No podemos olvidar, sin embargo, que el sistema de corporaciones gremiales ayudó a dotar tanto a los artesanos, en particular, como a los trabajadores no especializados, en general, de una cultura común a la par que distintiva. También las hermandades de trabajadores urbanos vascos tuvieron sus propios patronos, sus propias tradiciones y rituales $y$ organizaban el tiempo festivo de sus componentes de la misma manera que lo hacían con su trabajo. El gran acontecimiento anual de la cofradía, como es sabido, era la celebración de la fiesta del patrón al que estaba advocado el gremio. El día de San Crispín y San Crispiniano, patrono de los gremios zapateros vascos, todos los miembros del oficio, maestros, oficiales y aprendices, celebraban una misa en honor de los santos, acompañada casi siempre de procesiones que se dirigian a las iglesias matrices o salian de ellas, reparto de limosnas a los pobres y banquetes fraternales en los que todas las familias que componian el 
oficio se reunían para festejar y glorificar la identidad del colectivo. La celebración duraba hasta altas horas de la noche, con bailes, luminarias $y$, a veces, fuegos de artificio en los que se permitía y potenciaba la participación de todos los vecinos de las villas. Nunca como en las fiestas patronales de los gremios las corporaciones artesanas glosaban tan rotundamente el componente narcisista y lúdico que les identificaba y definia ante las vecindades. En las procesiones hacia la iglesia quedaba visualizado el amplio y profundo alcance de una comunidad de oficio moralmente articulada en segmentos verticalizados, comenzando por los veedores y mayorales que portaban la efigie del santo y las banderas del gremio, los maestros con sus familias, los oficiales con sus futuras esposas y, finalmente, los aprendices. Sus enseñas y vestuarios reflejaban la potencia de una comunidad constituida por hombres que se sentían «libres" y que habían prestado solemnes juramentos de lealtad y fidelidad, que eran hijos espirituales del mismo patrón y que lo veneraban colectivamente el día de su fiesta. Esto quizás explique los excesos en los comportamientos de los oficios artesanos durante tales días. Excesos que estaban directamente relacionados con la ingestión desmedida de alimentos y bebidas, con las subsiguientes actitudes burlescas y agresivas o con la risa sardónica y los rituales de júbilo y protesta jaleados por cada oficio y que, en mi opinión, todavía no conocen una evaluación sistemática y contrastada para el conjunto del ámbito territorial español.

Por lo demás, si algo podía expresar con una elocuencia lúdica e identificadora el interés de las hermandades artesanas por la generalidad de los agremiados era la posición central del entierro y la muerte en la vida ceremonial y simbólica de cada comunidad obrera. Es verdad que los estudios sobre la muerte en el pasado se han multiplicado en nuestro país en las dos últimas décadas, pero su significado en el mundo del trabajo es todavía parca e insuficiente. Debo subrayar que en tales casos, las cofradias de trabajadores preindustriales vascos se conformaron, de nuevo, como instancias morales que sabian trascender y reubicar sus múltiples identidades colectivas en la glorificación festiva de los lazos invisibles que unían a cada uno con el resto de los hermanos agremiados. Estar presente en la marcha fúnebre, llevar grandes hachones de cera blanca o amarilla, acompañar al colega difunto, siempre con un profundo sentido lúdico, era el último compromiso de los trabajadores juramentados. La muerte celebrada quedaba reforzada no sólo por un funeral corporativo, de obligada participación, en el que todos despedían al acólito desaparecido, sino también por rituales de agasajo, masculinidad y comensalidad, incluidas borracheras artesanas, que ensalzaban y 
fundían a los participantes más como una familia que había perdido a uno de sus más intimos integrantes que como a un simple conocido que había vivido y padecido las ilusiones y desesperanzas de la práctica organizada del oficio. De aquí que las corporaciones artesanas fuesen tan puntillosamente meticulosas en el seguimiento de los comportamientos funerarios de los adictos a cada gremio. No participar era una incitación a la crítica colectiva y la rebeldía a sus cánones una propuesta de exclusión, como fácilmente colegimos del acuerdo adoptado por la hermandad de San Antonio Abad, de maestros y oficiales armeros, herreros y "cualquier género de cosas de hierro" de la villa de Tolosa en enero de 1739:

«(...) habiéndosele pedido a Francisco Lacarra, cofrade armero, que pague quince reales de vellón que está debiendo a la Cofradía, de multas por no haber asistido al acompañamiento de los hermanos difuntos, respondió con mucho arrojo y cólera que no debia pagarlas y sin temor de Dios ni de su conciencia y en desprecio de la santa cofradia y de sus hermanos, blasfemó diciendo que todos los demonios del infierno los llevasen a los mayordomos y diputados de dicha cofradia, añadiendo que el mal rayo partiese a todos ellos, por lo que se pidió a todos los hermanos de la cofradia se de a Francisco Lacarra el castigo que merece conforme al delito en que ha incurrido para que sirva de ejemplar a otros hermanos que se propasasen en iguales maldiciones" ${ }^{4}$.

En efecto, las corporaciones artesanas vascas reforzaron sus señas de identidad colectivas festejando a sus patronos y enalteciendo colectivamente la memoria de sus miembros desaparecidos. Sin embargo, los compromisos vitales y festivos de los agremiados no quedaron reducidos a las dos iniciativas aludidas. Pertenecer a un oficio dignificaba al artesano, al mismo tiempo que lo cualificaba. Por supuesto, las mecánicas cualificadoras estaban fijadas social y culturalmente por el orden estamental que regía los entramados comunitarios urbanos. Dicho orden regulaba los derechos, prerrogativas y obligaciones que cada corporación debía cumplir a rajatabla, circunstancia esta que nunca dejó de ser una fuente de seculares y puntuales conflictos. Hemos de tener en cuenta que el estado absoluto otorgó, desde la Baja Edad Media, a la estructura gremial una entidad definitoria de sociedad corporativa, y como parte constitutiva de la trama de poderes instituidos estaba obligada a participar con sus insignias y símbolos en todas las grandes ceremonias y festejos de la ciudad en la que aquélla se asentaba. Todavía sabemos muy poco del organigrama cere-

4 Garmendia larrañaga, J., Gremios, oficios y cotradias en el País Vasco. Caja de Ahorros Provincial de Guipúzcoa. San Sebastián, 1977, págs. 259-260. 
monial preindustrial en el que se entremezclaban e interpenetraban las escenografías del poder con las teatralizaciones simbólicas y lúdicas que emergían desde la matriz de las distintas culturas plebeyas. Por ejemplo, en las procesiones artesanas vascas del Rosario, tan populares durante el Setecientos, no fue tan decisiva la capacidad movilizadora del oficio como las solidaridades vecinales y de amistad. Pero los sastres y los zapateros bilbaínos no hubiesen obtenido la adhesión de sus trabajadores y de las barriadas de Somera, Artecalle, Belosticalle y Tendería, sin la capacidad dinamizadora y culturizadora de los distintos cabildos eclesiásticos de la villa o el ulterior visto bueno de las autoridades seculares del Ayuntamiento y del Consejo Supremo de Castilla. Ahora bien, tampoco el patriciado laico y sacerdotal hubiese interiorizado una sensación de victoria sobre unos menestrales que cantaban y rezaban procesionalmente o se arrodillaban ante los nichos y altares desperdigados por las calles, sin que las corporaciones artesanas hubiesen dispuesto que tales ceremonias se realizaran preferentemente durante los Lunes Santos, dias en los que las tradiciones lúdicas y festivas obreras practicaban un absentismo laboral ancestral, y sin que, una vez concluido el encuentro religioso, los artesanos mecánicos y en general los miembros de las categorias populares hubiesen institucionalizado un recorrido ritual y multitudinario por la tupida red de tabernas que se extendían por la villa. Era, de alguna manera, otra forma de moralizar una costumbre festiva tan arraigada en la conciencia de un artesanado que, aun aceptando participar de los cánones teológicos que revelaba el discurso y la práctica procesional consagratoria de una divinidad femenina, era reacia a perder los elementos definitorios que tradicionalmente estaban asociados a semejante día, es decir, el descanso, la holganza y el reencuentro bullanguero en tascas, bodegones, tabernas y mesones. Se trataba de una concesión al impacto de la hegemonia cultural de las clases dirigentes y a la impronta ideológica que caracterizó aquella contemporaneidad histórica, para - a la postre- defender comportamientos convulsionarios de un día jubiloso. De nuevo, lo sagrado se malea con lo profano y el peso de su amalgama tendia a bascular en la dirección que privilegiaban las experiencias festivas plebeyas. ¿O no es este, acaso, el correctivo aplicado por los redactores del artículo trece del Reglamento de la Junta de Beneficencia de Valmaseda, fechado en 1773, y que debían cumplir a rajatabla los "pobres trabajadores» no organizados acogidos en su Casa de Misericordia?:

"Los domingos y fiestas deberán acudir a la misa mayor de cualquiera de las parroquias y por la tarde al rosario, procurando pasar lo demás del día en otras santas y diversiones honestas, teniendo cuidado de no embriagarse, o por hablar más claro, no emborracharse, porque si se le viera venir en tal es- 
tado al almuerzo, comida o cena no se les dará y en castigo se les privará el domingo o fiesta inmediata de la libertad que se les concede a todos" ".

Todos los hitos festivos, insisto en subrayarlo, que podamos rastrear en el pasado histórico de las categorías populares productivas tendieron a ser filtrados por las distintas estructuras de los poderes instituidos al objeto de lograr un alineamiento colectivo. Más aún, aquéllas siempre intentaron adueñarse de sus latidos para trocarlos en ceremoniosas politologías idealizadoras que redundasen en la ampliación y reciclaje de los cimientos en los que se asentaban sus legitimidades y dominios. La apelación a la participación ordenada y pública de los trabajadores juramentados durante las fiestas del Corpus Christi es, sin duda ninguna, el mejor y mayor paradigma de lo señalado hasta aquí. Los espectáculos religiosos representados en muchas villas vascas durante ese día fueron, a menudo, organizados sobre la base de las corporaciones artesanas, como también lo eran numerosos espectáculos profanos. Procesiones, representaciones teatrales, corridas de toros, cucañas, bailes campestres, gigantes y cabezudos, juegos de rudeza y un largo etcétera se concitaban para encuadrar el júbilo de una multitud enardecida, que respiraba los aires de una "cuestión religiosa" que, por aquel entonces, era vivida con una profunda emotividad. También en este apartado específico del festejo subalterno debemos ser meticulosos con las metamorfosis que se operaron a lo largo de los siglos. Sin entrar en profundidades, que aquí no vienen al caso, para que se entienda lo que pretendo decir, citaré el siguiente ejemplo: todavía en 1570 eran los mayorales de la Cofradía de San Sebastián de Durango (pañeros), los que junto a los de San Martín (guarnicioneros), estaban encargados de solicitar dinero y organizar el programa del Corpus de la villa. A partir del siglo XVII serán únicamente los cofrades de San Martín. Su peso en el campo de la producción artesana urbana hace que sean ellos los dueños de la fiesta o, para ser precisos, los detentadores de su desarrollo. Sin embargo, si fuese posible superponer dos imágenes fijas del mismo festejo, una correspondiente al siglo XVI y otra al XVII, constataríamos que las premisas normativas en las que se asentaba el programa festivo obrero del Quinientos hacian especial hincapié en dar protagonismo a las concentraciones en espacios eclesiásticos cerrados, mientras que durante la Centuria de Hierro los menestrales guarnicioneros durangueses privilegiaban la calle, la campa y los "templos populares", o sea, las ta-

Archivo Histórico Municipal de Valmaseda (A.H.M.V.). Libro de la Junta de Beneficencia de Valmaseda. Año 1783. Reglamento y Constituciones que deben observar y cumplir los pobres trabajadores que se recogen en la Casa de Misericordia, para su aprovechamiento espiritual y temporal. que se les deberá leer algunas veces al año. Articulo 13. S.f. 
bernas. Claro que entre ambos escenarios del mismo complejo festivo había mediado Trento, con su prolijo ideario de disciplina en los comportamientos y conductas lúdicas del artesanado católico europeo. Lo dicho para los festejos del Corpus Christi es aplicable a una de las celebraciones más genuinamente populares de la cultura burlesca subalterna. Me estoy refiriendo a los carnavales. Con frecuencia hemos podido constatar que el énfasis analítico promovido para reconocer sus significados en el seno de las comunidades preindustriales ha quedado circunscrito casi exclusivamente a los ámbitos rurales, sin considerar que los inmediatos dias que precedían a la Cuaresma en las áreas urbanas fueron determinantes para lubrificar, después del ciclo festivo navideño, el complejo ritual que detentaba y jaleaba el organigrama corporativo artesano. Los historiadores tenemos que agradecer la enorme aportación interpretativa generada por la etnografía, la antropología o la sociologia, disciplinas científicas que han agrandado nuestro conocimiento del carnaval. Pero hablar de agradecimiento no significa caer en el anonadamiento seguidista. Nuestra obligación y principal objetivo es descubrir y resaltar su historicidad evolutiva, caracterizar los juegos de inversiones que patentizaban los actos burlescos, las ceremonias groseras o las bromas pesadas ejecutadas por los trabajadores, evaluar sus impactos en la quebradiza armonía de los talleres artesanos, sobre todo allá donde oficiales y aprendices tenian franquicia para mofarse de maestros y consortes y, lo que es más importante, rastrear la mecánica simbólica - con reiterada frecuencia, de conflicto-que, promovidas por muchas generaciones de trabajadores mecánicos especializados o sin especializar, forjó una costumbre lúdica y una memoria común en las que, bajo una apariencia festiva, quedaron enumerados y superpuestos las estructuras emotivas, los sistemas de valores, las elecciones morales o las prácticas de repudio y castigo de la también distintiva cultura carnavalesca artesana.

Ya se ha resaltado arriba que las corporaciones de oficio eran unidades reconocidas de una sociedad corporativa y como cuerpos legitimados del Estado Absoluto, los gremios estaban obligados a participar con todos sus integrantes y emblemas en las grandes ceremonias del poder, en la coronación y en las recepciones y tomas de posesión del rey y otros grandes personajes, así como en las festividades que recordaban las victorias del Príncipe, bodas reales o mortuorios monárquicos, sin olvidar su onomástica o los nacimientos de las familias principescas. Sin embargo, el andamiaje argumental que ha distinguido la abundante bibliografía de la "fiesta monárquica" ha tendido, por regla general, a obviar aquel protagonismo o, como mucho, a hacerle partícipe -permítaseme la expresión- en grado de comparsero. Aquí no se puede argüir la carencia 
de fuentes. Sería de un cinismo superlativo por parte de aquellos historiadores con años de experiencia archivística o de una ingenuidad manifiesta por parte de los aprendices de la Historia. El hecho de que la masa artesana enalteciese o festejase con deleitación colectiva las escenografías sublimadoras del poder monárquico no debe ni puede sorprendernos. No cabía otra alternativa porque simplemente no la tenían y, además, se la imponían. Claro que los productos culturales de las clases dirigentes, siendo dominantes, no necesaria ni inequívocamente son dominadores. Trataré de explicarlo. Es verdad que en la fiesta monárquica todo el contingente poblacional de una ciudad preindustrial está convocado jerárquicamente a remedar con algarabía y júbilo la gloria del Trono y del Altar. Pero la participación nunca es caótica y unidireccional. Las categorías sociales aparecen y se desplazan compartimentadas, transportando todos los resortes culturales en los que viven y respiran su especificidad histórica. Por muy impactante o alienante que resulte un cortejo festivo monárquico, la presencia de símbolos de los menestrales manufactureros nunca es equiparable a las iconografías festivas que detentan o proyectan, por ejemplo, los patriciados linajudos, los cabildos eclesiásticos, los tenderos acaudalados o los miembros y familias de las casas de comercio. Indudablemente, tales cortejos constituyen politologías festivas que anhelan, en su verticalidad jerarquizadora, refrendar el statu quo vigente y aunque el paternalismo corporativo artesano no se aleja de sus máximas discursivas, las posibilidades de penetración de las tradiciones burlescas y los rituales festivo-punitivos obreros por los intersticios de una fiesta concebida ordenadamente son infinitas. Los cientos de expedientes que en los últimos años he podido consultar son, en tal sentido, tan aleccionadores como concluyentes. Cuando el Concejo de la villa aduanera vizcaína de Valmaseda, en junio de 1814 , convocó a todos sus vecinos a una fiesta que honrase la subida al trono del "Deseado", fue muy diligente en la preparación del solemne Te Deum, en la habilitación y limpieza de las calles por donde debía transitar el séquito de las "personas de distinción", en la fijación de los retratos y ornamentos reales en la balconada del consistorio, en la publicación y remisión de las esquelas e invitaciones a las "señoritas principales" de la villa y de la nobleza comarcana para que acudiesen a un baile de etiqueta nocturno en los salones del ayuntamiento (lógicamente el populacho quedaba excluido) o en el derroche de salvas de artillería y repiqueteo de todas las campanas de la jurisdicción, pero cedió todas sus atribuciones al poderoso gremio calderero de la villa para que este organizara la fiesta popular, tal y como siempre lo había hecho, con los inevitables bailes públicos en la plaza mayor, cohetes y voladores y corrida de novillos. No se trataba, como cabria suponer, de una cesión gratuita. Sólo los trabajadores organizados 
podían llamar a las categorias culturales homónimas —léase, la muchedumbre - para disfrutar de sus tradiciones lúdicas y festivas, que en buena medida han quedado oscurecidas o minimizadas por la solemnidad y aparatosidad artificiosas con las que los inflacionarios opúsculos impresos del festejo monarquista han inundado nuestros archivos y lamentablemente polucionado, el análisis de muchos de nuestros colegas y amigos. Sería importante otorgar al festejo monárquico la trascendencia que tuvo. Pero nada más. En él se superponian otras iniciativas que nada tenian que ver con sus objetivos. Que a veces se lograsen es una cuestión que merece una investigación más rigurosa y menos especulativa, centrando el núcleo de la cuestión más en el impacto sobre los hombres que en la recreación prosaica de las escenografías y coreografías imaginadas. Con todo, si nos empeñamos en proseguir los derroteros que hasta ahora se han privilegiado sería, en mi opinión, más interesante estudiar por qué, cómo y de qué manera el orden estamental antiguorregimental asumió el valor añadido que suponía la concesión como válvula oxigenadora para trabar la cohesión interclasista urbana, sabiendo además que facultar poder de gestión cultural — si bien, subsidiariamente- a los menestrales durante los festejos de etiología monárquica suponía, finalmente, apuntalar el ya de por sí vigoroso programa festivo artesano. De igual manera, podríamos interrogarnos hasta qué punto la instrumentalización y subordinación subsiguientes que reivindicaban los rituales del Trono sirvieron de argamasa para objetivar, cohesionar y dar carta de naturaleza legitimadora y exaltadora a los distintos idearios políticos del ultrarrealismo subalterno europeo, sin duda muy expansivos y vivificadores durante el primer Ochocientos, precisamente cuando el liberalismo y los distintos socialismos proletarios disponian de unos modelos muy desarrollados de trabajo, distracción y fiesta. Es posible que si reflexionáramos sobre las cuestiones expuestas aquí podríamos entender y explicar de una manera más adecuada el por qué las autoridades valmasedanas, tan poco proclives al desorden en las diversiones sociales, no vieran con malos ojos o no sintieran temor cuando, concluido el festejo taurino, irrumpió en el coso una comitiva de jóvenes oficiales caldereros para representar un charivari político grotesco en el seno de un espectáculo público que escalonaba la praxis sublimadora de la entronización de un rey tan mezquino:

“(Los jóvenes trabajadores) conducian las efigies de Napoleón y de su hermano Monsieur Jose en Francia y don José en España, vestidos de generales y montados sobre dos asnos, que eran conducidos a ser despedazados por la artillería. El gracioso pregón que precedía a la comparsa, las botellas que rodeaban a don José, las extravagantes decoraciones de su 
hermano y el ridiculo modo como se realizó el simulacro, exaltó más y más la alegría que reinaba y retrataron más al vivo la teatral farsa que estos dos extraños personajes han representado en Europa" ${ }^{6}$.

Es difícil sintetizar mejor, en el breve espacio de unas líneas, la suma de experiencias y tradiciones culturales obreras que esboza este teatro de la burla y del absurdo populares. Se representaba el juicio a dos reos con espantosos cargos de crímenes de lesa humanidad y que eran leídos y pregonados para general conocimiento público a semejanza de los malhechores locales. La conciencia patibularia plebeya les había condenado a la muerte. El pregón era un bando jocoso de los delitos de aquellos dos hombres que eran los últimos responsables de la quema y destrucción de la villa durante los penosos años de la Guerra de la Independencia. Don José era, además, representado como un borracho impenitente y su hermano Napoleón I como un jactancioso "militarote" que cubría su dorso con unas "decoraciones extravagantes" y que muy probablemente simbolizaran todas las fobias punitivas que rechazaba la sociabilidad subalterna. Ambos eran trasladados al cadalso sobre asnos, tal y como se practicaba con los vulgares delincuentes sociales, para ser despedazados por fuerzas artilleras, es decir, los cañones que el vulgo había tenido que usar para rechazar y expulsar a los ejércitos invasores. La farsa era un teatro que invertía la dramatización del control de los poderosos sobre las categorías trabajadoras a través del terror del ejemplo, pero aquí -al contrario de lo que practicaba la judicatura del Estado Absoluto- no había sangre y muerte, sino alegría y risa compartidas. En definitiva, el ritual teatral artesano reflejaba y resumía un acto de liberación colectivo.

Hasta ahora hemos incidido en las corporaciones artesanas como instancias constitutivas del festejo obrero. En el futuro, la historiografía española deberá ser más exigente y plantearse cuestiones trascendentales como la regulación del tiempo de trabajo, las formas lúdicas del absentismo laboral en los talleres artesanos, las cambiantes y adaptativas tipologias de juegos concluidas las jornadas laborales, así como los escenarios y sus participantes y protagonistas, las recreaciones familiares dominicales, los consumos de bebidas en tabernas, las tertulias artesanas, los ágapes y comilonas colectivas obreras, los rituales festivos que jalonaban y entronizaban los pasos de condición entre el aprendizaje, la oficialía y la maestría, el lenguaje soez, las conductas informales y no

Hefros, M. de los, Historia de Valmaseda. Amigos del Libro Vasco. Bilbao, 1988. Vol. II, págs. 510-511. El desarrollo de la fiesta y el extracto del charivari politico son un documento de la Biblioteca Nacional que de los Heros transcribe en el apéndice de notas del volumen citado. 
respetuosas y los ceremoniales burlescos de los trabajadores solteros en relación a un mundo del trabajo concebido tan regulada como jerarquizadoramente, el permanente anhelo de aventura, abandonando los aprendices los talleres y recorriendo los oficiales las romerías, mercados y festejos de las culturas campesinas, la frecuentación de burdeles, la penetración de la cultura letrada y sus impactos sobre el tiempo de no trabajo de los asalariados, el uso privilegiado de un vestuario específico como garantía identitaria de la práctica de cada uno de los oficios, en definitiva, estudiando más intensamente todos los valores culturales e históricos que subyacian en las conciencias de los trabajadores preindustriales, entre los que destacaria los siguientes: una anamórfica concepción del trabajo honrado, un salario justo, una apelación continuada a la vivificación de los derechos tradicionales para ellos y sus familias, la menor división del trabajo que fuera posible y la defensa a ultranza del descanso intenso para paliar los sinsabores del trabajo manufacturero frenético. Todas las variables de investigación y análisis que señalo forman parte del denso programa sobre la Cultura Artesana que otras prácticas historiográficas, especialmente las anglosajonas y centroeuropeas, han emprendido desde hace décadas con resultados que podrian adjetivarse de fructíferos. La riqueza de nuestras fuentes documentales también permiten avanzar en todos los frentes indicados arriba. Las actuaciones que deben llevarse a cabo no se agotan, ni mucho menos, con las líneas de trabajo que he manifestado. Con su enumeración tan sólo he tratado de sugerir aquellos capítulos centrales que, a mi entender, mejor caracterizarian o explicarian los modos de vida de los trabajadores cualificados preindustriales, los estándares socioculturales de resarcimiento y diversión que tendian a desarrollar para contrarrestar las rigurosas condiciones de producción de mercancias a pequeña escala en las que ellos y sus familias estaban inmersos y las formas lúdicas, festivas y recreativas que potenciaban cada día para ejercer el consuelo de sentirse, al unisono, pobres, honrados, dignos y libres.

Aunque aquí no puedo adentrarme en una exhaustiva reflexión sobre cada una de las cuestiones enunciadas, si me gustaría plantear algunas pautas dialécticas de la ecuación trabajo-no trabajo y su incidencia en la conformación de la cultura lúdica artesana. Para empezar, seria conveniente y obligado repensar y reubicar los testimonios y los discursos de los intelectuales ilustrados, tan entusiastas en favorecer la lógica de libre mercado y tan celosos de las normas disciplinadoras que debian regir el régimen laboral en las primeras fases de la industrialización. A los muy conocidos de Floridablanca, Ricardo, Jovellanos, Smith, Foronda o Capmany, podríamos aquí añadir, por ejemplo, algunos más desconocidos, como los 
del economista bilbaino N. de Arriquibar o los del escritor francés N. E. Restif de la Bretonne, para quienes las necesidades obreras quedaban reducidas a la inversión de su fuerza de trabajo - icuanto más breve fuera el lapso temporal, mejor! - al objeto de obtener una renta salarial que les dispensase del desasosiego y la esclavitud del trabajo. Sus conclusiones coinciden hasta tal extremo que, pareciendo un plagio, son reveladoras de las dificultades que hubo de superar el primer capitalismo para imponer la regularidad del trabajo en el proceso productivo. Y así, si para el pensador español, los más sobresalientes oficiales que había en cada arte "se contentan con trabajar tres o cuatro horas al día, empleando el resto en la diversión" ${ }^{7}$, para el disoluto y brillante narrador de las costumbres festivas francesas durante los años de la Revolución, los trabajadores parisinos no quedaban a la zaga y "si pueden ganar lo que necesitan en tres dias trabajarán nada más que tres dias y descansarán los otros cuatro" ${ }^{8}$. Era tal el derroche y la inversión de los artesanos en actividades no productivas, relacionadas muchas de ellas con el descanso, la holganza y la diversión, que los pensadores del Setecientos no dudaron en etiquetar semejante disenso como actos de vagancia y malentretenimiento, llegando incluso a calificarles como los dos pecados capitales de los trabajadores vascos y europeos y de presentarlos como la más segura antesala de la pobreza, la mendicidad y la criminalidad, males incorregibles que eran fuente para quebrantar la autoridad y energía para enaltecer los sentimientos de rebeldía. Esto explica el corpus represivo con el que se dotó el Estado Absoluto en materia laboral y las normas que irradió a todas las instancias jurisdiccionales de los distintos reinos occidentales, susceptibles todas ellas de transformar el absentismo laboral festivo en materia delictiva y, en consecuencia, en comportamiento corregible con la cárcel o la leva forzosa, como fácilmente advertimos de la lectura del decreto promulgado por el ayuntamiento de la villa ferretera de Ochandiano en el verano de 1743:

“(..) muchos oficiales y gentes de todo género de trabajo, por no trabajar y hacer mal daño a sus amos andan jugando los días de labor; otros pudiendo trabajar y teniendo habilidad andan molestando y enfadando con sus burlas a la gente y otros trabajadores en los días de labor; y los días de fiesta y de trabajo salen a pedir limosna en grandes grupos con músicas y ruidos para hacer meriendas y comilonas (...). En adelante se tenga especial cuidado y vigilancia por los Señores Justicia para que ninguno juegue en los días de

ArRiQuibar, N. DE, Recreación Política. Tomás de Robles y Navarro, impresor. Vitoria, 1779. Vol. II, Carta IV, pág. 67

8 Restif de la Bhetonne, N. E., Les Nuits de Paris. UGe. París, 1963, pág. 127 
labor y sólo se permita el que los oficiales de fraguas están ociosos un día a la semana y fuera de él, si se hallaren sin trabajar, como bebiendo y jugando sean presos en la cárcel pública, y si reinciden sean remitidos al servicio de S.M. ${ }^{9}$.

Por lo demás, podría parecer quizás que los productores artesanos constituian una masa disoluta, sólo movilizada por el permanente empeño de la diversión y la fiesta. Si esa fuera la imagen descollante que proyecta la lectura de lo anteriormente expuesto no dudaría en calificar la visión de espejismo desacertado, cuyo último responsable sería el que suscribe estas páginas. Debe tenerse en cuenta que el artesano percibia su trabajo de forma muy diferente a la del obrero industrial contemporáneo. Su labor transcurría medida por aquello que estaba creando, un par de zapatos en el caso de un trabajador de obra prima, una faltriquera en el caso de un oficial sastre, un millar de clavos por parte de un herrero, etc. Era el objeto el que daba el valor al trabajo. El valor de uso seguia dominando la producción. Dominar el trabajo, conocer los mas íntimos secretos de la práctica del oficio, durante la larga fase protoindustrial, significaba - con todas las consecuencias que de semejante hecho se derivaban y que en el futuro han de ser investigadas- dominar el tiempo productivo. La moral de la aplicación y asiduidad en el trabajo, tan característica de la cultura corporativa artesanal, aunque con frecuencia se olvida, se fundaba en la preocupación por dar una asignación concreta al tiempo y sus exigencias productivas. El maestro del taller demandaba de sus productores directos, oficiales y aprendices, disciplina y rigurosidad en la elaboración manufacturera. Por su parte, los menestrales que estaban sujetos a la dirección de aquél apelaban a sus destrezas, diligencias y conocimientos del oficio para quebrar la permanente presunción de holgazanería con la que tan frecuentemente los propietarios de los medios de producción y la inteligencia ilustrada tildaban las actitudes laborales y no laborales de los trabajadores preindustriales. La controversia entre una moral de laboriosidad activa, reivindicada por maestros, y una aplicación honrosa de la jornada

Archivo Histórico Municipal de Ochandiano (A.H.M.O.). Libro de Actas, $n^{\circ}$ 5. Acuerdo del Ayuntamiento, 1743-Agosto-11. Folio 85. El absentismo, las libaciones tumultuarias para festejar festejos artesanos y la distribución irregular del tiempo de trabajo por parte de los oficiales meta. lúrgicos no quedaron conculcados por este decreto municipal. Sesenta años más tarde. los re. presentantes del Ayuntamiento, quienes además eran los propietarios de los numerosos talleres existentes en la villa, volvían a denunciar los modelos de cohesión social que jaleaban los menestrales en sus encuentros festivos: "Se ha hecho presente que muchos oficiales de las fabricas de herraje y clavo de esta villa pasan a la venta-taberna de Gomilaz los dias festivos y de labor y se mantienen de día y de noche, comiendo, bebiendo vino y jugando y dando sospechas de su mal proceder, sin que hubiese medios para contenerlos ni corregirlos" (A.H.M.O. Libro de Actas, $n^{\circ}$ 6. Acuerdo del Ayuntamiento. 1804-enero-28. Folios 29-30). 
de trabajo, salpicada de múltiples tiempos no productivos, defendida por los asalariados, se convirtió desde la Alta Edad Moderna en expresión de una lucha por asignar al tiempo un uso concreto; uso concreto que para los primeros era una relación que vinculaba el trabajo con la producción, y para los segundos una ecuación múltiple que basculaba entre el trabajo digno, la mercancía bien ejecutada, el salario justo y el descanso prolongado. $Y$ es que para muchos artesanos preindustriales, que vivian dependientes de la obtención de un salario, la no posesión de los medios de producción no comportaba, como consecuencia, la exclusión de algún control del proceso de producción efectivo y concreto. La asunción de este control significaba a menudo escapar del aislamiento que les imponían los talleres artesanos, buscar la sociabilidad de la taberna, informarse alli de los precios de las hechuras que producían o de las condiciones de trabajo en los otros talleres del oficio, jugar hasta la extenuación unos cuartillos de vino, cantar coplillas jocosas contra los amos, emborracharse o escuchar con complacencia los chismes misóginos de la barriada, para al final regresar a los "tugurios productivos", tal y como les denominaban los trabajadores del Tour de la France en el primer tercio del siglo $x \mid x$, en los que habrian de cumplimentar interminables jornadas diarias de entre doce y catorce horas de trabajo continuo. Por eso, para la inmensa mayoría de los trabajadores conocedores de un oficio, la elección del descanso vivido frenéticamente, lejos de ser un capricho se reveló como una necesidad, sólo comprensible en el complejo marco evolutivo de la cultura lúdica y festiva del artesanado preindustrial subalterno vasco y europeo. 